\title{
Psychosocial Factors in Marital Satisfaction among Married couples in Benin-City: An Implication for Couple's therapy.
}

\author{
Aroyewun B. Afolabi \\ Department of Psychology, Chrisland University \\ Owode-Abeokuta, Ogun State, Nigeria \\ Adeyemo S. Oladotun \\ Department of Psychology, Olabisi Onabanjo University \\ Ago-Iwoye, Ogun State, Nigeria \\ Ezemokwe 0. Chinedu \\ Clinical Psychology Unit, Federal neuropsychiatric Hospital \\ Uselu, Benin-city, Nigeria \\ Oyeyemi E. Tolulope \\ Department of Psychology, University of Lagos \\ Lagos, Lagos State, Nigeria
}

\begin{abstract}
Marital satisfaction continues to be a significant phenomenon in the present day marriages. However, there has been a significant increase in the numbers of couples that come for couple's therapy in the last one year. Therefore, this study on the communication pattern, gender and age on marital satisfaction. 200 married couple was conveniently sampled. Index of Marital satisfaction and Primary Communication Inventory were used to measure marital satisfaction and communication pattern respectively. Chi-square analysis was used to investigate the relationship amongst all the variables. The result showed that there was a significant relationship between gender and marital satisfaction $\left(X^{2}=11.591 ; \mathrm{df}=1 ; \mathrm{p}<0.05\right)$, also, there was significant relationship between communication pattern and marital satisfaction $\left(X^{2}=23.683\right.$; $\mathbf{d f}=1 ; \mathbf{p}<0.05$ ) while there was no significant relationship between age and marital satisfaction $\left(\mathrm{X}^{2}=0.207 ; \mathrm{df}=1 ; \mathrm{p}>0.05\right)$. It can be concluded that gender and communication have significant relationships on marital satisfaction and as such should be a focus in couple's therapy.
\end{abstract}

Keyword: Psychosocial, Marital Satisfaction, Married couples, Benin-City

\section{INTRODUCTION}

The importance of marriage is as old as the (pre)recorded history of man, (Gen 2:18). And cultures the entire world over have testified to this importance as no culture exists which does not believe in man-woman relationship, no matter how inadequate this may seem. For example, divorce rates continue at an alarming rate; there was reported to be about 12,000 number of divorce cases in Nigeria from 1975, (Almanac Book of Facts, 1977) and, also, there was report of domestic violence (Oladepo et.al., 2011), yet marriage continues to be an enduring sociocultural institution boasting of 48, 924, 317 numbers in 2006, (National Bureau of Statistics, 2010). 
One of the most researched factors for continuous relevance of marriage is marital satisfaction. Either defined as the amount of contentment that a couple feels about their relationship, (Rowe, 2004) or as a subjective evaluation by an individual of the degree of happiness, pleasure, or fulfillment experienced within the marital relationship between spouse and self, (Rho, 1989), or in the definition of Gilford \& Bengtson (1979) as spouses' evaluation of their relationship on two general dimensions: positive interaction and negative feeling, or Hundson's (1982) definition in the degree, severity or magnitude of problems one spouse or partner perceives to be having in the marital relationship with his or her partner and or Akanbi's (2002) definition of marital satisfaction as an extent to which partners in marriage have a sense of accomplishment or fulfillment of the mutual needs, goals and expectation in marriage; its significance cannot be overlooked.

There is confirmatory evidence of the difference between the way a man and a woman will fare on marital satisfaction, (Johnson \& Lebow, 2000; Walker, 1999). Essentially, marriage could be described as a relationship with benefits for men than women, because men are more satisfied in their marriages than women, (Clements \& Swensen, 2000, Baslow, 1992; Heyn, 1997, Schumm, Webb, \& Bollman, 1998) and women have more negative experiences than men, (Heaton \& Blake, 1999), and this seems to be similar in cultures around the world, (Rhyne, 1981, Basat, 2004).

Couples' age can affect marital satisfaction either positively or negatively. Those who marry in their teen age experience worst of marital satisfaction because of some social threats to marriage, (Stanley \& Markman, 1997), contrastively, 20 agers experience more marital satisfaction, (Tzeng, 1992).

Another factor contributing to marital satisfaction is communication pattern. Couple's communication pattern has a rewarding significance to marital satisfaction. A communicating couple is in a marital satisfying relationship, (Kirchler, 1989, Rogge \& Bradbury, 1999).

This study was aimed at investigating the significant relationship of demographic variables (age and gender) and communication patterns between the spouses on marital satisfaction of married couples in Benin-City as personal observations of these researchers/authors have revealed that numbers of couples that come for couple's therapy have increased in the last one year.

The result of the study would supply an added scientific reason to clinical psychologists both in teaching and practical field of couple's therapy about the reality of factors that can influence marital satisfaction.

\section{Participants and Procedure}

\section{METHODS}

Cross sectional research design was used as the research design and the participants' were conveniently derived. This was basically to get more and robust participants in as very short time as possible. The study was carried out in Benin City and its environs with questionnaires given to individual participants whether the husband or wife alone or to both of them as the situation may provide after their consent had been duly sought. A total of 200 married couple was used for this study. Male participants were $114(57 \%)$ and female participants were $86(43 \%)$ with age range $26-65$ with mean age of 38.67 and SD of 8.33 . 


\section{Data Analysis}

Statistical Package for Social Sciences software, 17 (SPSS 17) was used to analyze the data. At $\mathrm{P}<0.05$ level of confidence was considered significant, frequency and Chi-square analysis were used to analyze the data.

\section{Research instruments}

Marital satisfaction was measured with Index of Marital satisfaction scale developed by W.W Hudson (1982) to measure problems associated with marital satisfaction. It is a 25 -item inventory designed to measure the degree, severity or magnitude of problems one spouse or partner perceives to be having in the marital relationship with his or her partner. IMS is administered individually or in groups after establishing adequate rapport with the client. In scoring IMS items 2,4,6,7,10,12,14,15,18,22,24,25 are scored directly while items $1,3,5,8,11,13,16,17,19,20,21,23$ are reverse scored, final score is obtained by adding together the results of the direct scores and the reverse scores to obtain the client's raw score. Subtract 25 from the raw score to obtain the client's final score. The norms for Nigerian samples young adult M \& F is 38.84. The reliability coefficients reported by Hudson (1982) are: Cronbach's alpha internal consistency $=.96,2$-hour test-retest $=.96$. A concurrent validity of .48 was obtained by Anene (1994) by correlating IMS with Marital Stress Inventory (MSI) (Omoluabi, 1994). The Primary Communication Inventory (PCI) by Locke, H.J, Sabaght, F., \& Thomes, M. M. to measure the degree and pattern of communication in marriage between husband and wife or spouses. The 25-item inventory is designed to assess the quality of both verbal and nonverbal communication between husband and wife in different social settings and social interactions. It is administered individually or in groups after establishing adequate rapport at with the client. In scoring PCI items 8, 9, 15, 17 are reverse scored while the other items are directly scored. The norms for Nigerian samples are: 93.41 for husband and 76.80 for wives. The reliability and validity obtained by Omoluabi (1999) are as follows: Cronbach Alpha $=.72$, test retest $=.84$, concurrent validity coefficient of .69 by correlating PCI with Marital Stress Inventory (Omoluabi, 1994).

RESULT

Table 1: socio-demographics of study participants

\begin{tabular}{llll}
\hline & Response & Frequency & \% \\
\hline \multirow{3}{*}{ Gender } & Male & 114 & 57 \\
\multirow{2}{*}{ Age } & Female & 86 & 43 \\
& Total & 200 & 100 \\
& Minimum & Maximum & Mean (SD) \\
\hline
\end{tabular}

Table 1 above shows that 114 (57\%) of the participants were male, while 86 (43\%) were female. The age of the participants in the study ranges from 26 to 65 with a mean age of 38.67years and standard deviation of 8.33. 
Table 2: summary table of cross-tabulation of gender, age, primary communication and marital satisfaction

\section{Marital satisfaction}

\begin{tabular}{llllllll}
\hline & & Normal & Poor & Total & df & $X^{2}$ & P \\
& Male & $74(64.9 \%)$ & $40(35.1 \%)$ & $114(100 \%)$ & & \\
Gender & Female & $35(40.7 \%)$ & $51(59.3 \%)$ & $86(100 \%)$ & 1 & 11.591 & $<0.05$ \\
& Total & $109(54.5 \%)$ & $91(45.5 \%)$ & $200(100 \%)$ & & \\
& Young & $61(56.0 \%)$ & $48(44.0 \%)$ & $109(100 \%)$ & & \\
\hline \multirow{2}{*}{ Age group } & Old & $48(52.7 \%)$ & $43(47.3 \%)$ & $91(100 \%)$ & 1 & 0.207 & $>0.05$ \\
& Total & $109(54.5 \%)$ & $91(45.5 \%)$ & $200(100 \%)$ & & \\
\hline \multirow{2}{*}{ Communication } & Poor & $32(35.6 \%)$ & $58(64.4 \%)$ & $90(100 \%)$ & & & \\
& Satisfactory & $77(70.0 \%)$ & $33(30.0 \%)$ & $110(100 \%)$ & 1 & 23.683 & $<0.05$ \\
& Total & $109(54.5 \%)$ & $91(45.5 \%)$ & $200(100 \%)$ & &
\end{tabular}

Table 2 shows significant relationship between gender and marital satisfaction $\left(\mathrm{X}^{2}=11.591\right.$; $\mathrm{df}=1 ; \mathrm{p}<0.05)$ with $74(64.9 \%)$ male and $35(40.7 \%)$ female satisfied with their marriage, also primary communication was significantly related to marital satisfaction $\left(X^{2}=23.683\right.$; $d f=1$; $\mathrm{p}<0.05)$ with $77(70.0 \%)$ of participants having satisfactory communication reporting normal marital satisfaction. However, age group of participants did not significantly relate to marital satisfaction $\left(X^{2}=0.207 ; \mathrm{df}=1 ; \mathrm{p}>0.05\right)$

\section{DISCUSSION}

This study investigated the relationship between gender, age and communication on marital satisfaction. The result suggested that gender has a significant role to play in marital satisfaction with men experiencing more marital satisfaction than women. This is sounding similar sentiments of earlier studies on these variables, as reported by the studies of (Johnson \& Lebow, 2000; Walker, 1999 and Clements \& Swensen, 2000). A man and a woman basically start marital relationship; the way it turns out depends on the two of them.

Also, communication was found to be another significant factor in marital satisfaction. The studies of (Kirchler, 1989, Rogge \& Bradbury, 1999) had same evidence. The more a couple's communicate, the less crack in marital relationship.

However, age was singled out as having no significance on marital satisfaction. Previous studies have not had a particular direction on this variable as some age brackets have found to be more significant on marital satisfaction than others; people who marry in their twenties tend to experience more marital satisfaction (Tzeng, 1992) than those who marry in their teens, (Stanley \& Markman, 1997). This result maybe because of the age brackets considered in this study (26-65). 


\section{IMPLICATION AND CONCLUSION}

The results of the study have salient implications for practical field of couple or marital therapy. It should be emphasized in therapies that a man and woman enter into marital relationship and they owe it to themselves to talk it through better by engaging in positive communication patterns. Another implication on age is that age is just an ordinary number; it may not necessarily determine satisfaction in marriage, hence, it should be an important factor in premarital counselling for intending couples.

In conclusion, gender and communication have significant relationships on marital satisfaction and as such should be a focus in couple's therapy.

\section{LIMITATIONS}

The sample technique (convenience non probabilistic) of this study posed problem of representativeness to the number of participants finally used. As it may be noticed, there was skewness to more male than female in the study.

We cannot reliably generalize the usefulness of the results from this study because of another reason of setting which was restricted to Benin and its environs.

Also, the result should be used with caution especially when we consider other important variables which can potentially influence marital satisfaction. Therefore, further studies should be encouraged to know more about these other variables.

\section{Reference}

Akanbi, S.T. (2002). An investigation of the factors determining marital satisfaction among elites in Ogbomosho land. Unpublished Master's Thesis Department of Guidance and Counselling. University of Ibadan, Ibadan Almanac Book of Facts, 1977.

Anene, R. N. (1994). A comparative Analysis of marital stress. Unpublished B.Sc Thesis, Department of Psychology, University of Lagos.

Basat, Ç. (2004). An exploration of marital satisfaction, locus of control, and self-esteem as predictors of sexual satisfaction. Unpublished master's thesis, Middle East Technical University.

Baslow, S. A. (1992). Gender: Stereotypes and roles. (3rd Ed.). Pacific Grove, CA: Brooks/Cole.

Clements, R. \& Swensen, C.H. (2000). Commitment to one's spouse as a predictor of marital quality among older couples. Current Psychology, 19(2), 110-120.

Gilford, R., \& Bengtson, V. (1979). Measuring marital satisfaction in three generations: Positive and negative dimensions. Journal of Marriage and the Family, 41, 387-398.

Heaton, T.B. \& Blake, AB. (1999). Gender differences in determinants of marital disruption. Journal of Family Issues, 20(1), 25-46.'

Heyn, D. (1997). Marriage shock: The transformation of women into wives. New York: Villard.

Hundson, W. W. (1982). Index of marital satisfaction. The Clinical Measurement Package: A Field Manual. Chicago: Dorsey Press.

Johnson, S., \& Lebow, J. (2000). The "coming of age" of couple therapy: A decade review. Journal of Marital and Family Therapy, 26, 23-38.

King James Version Bible (2013).

Kirchler, E. (1989). Everyday life experiences at home: An interaction diary approach to assess marital relationships. Journal of Family Psychology, 2, 311-336

Locke, H. J., Sabaght, F., \& Thomes, M. M. (1967). Communication and adjustment in marriage. Family Process 6, 173-184. 
National Bureau of Statistics, Annual Abstract of Statistics, Federal Republic of Nigeria. (2010).

Oladepo, O., Yusuf, O.B., \& Arulogun, O.S. (2011). Factors Influencing Gender Based Violence among Men and Women in Selected States in Nigeria. Afr J Reprod Health 15[4]: 78-86

Omoluabi, P.F. (1994). Psychosocial causes and remedies of single parenthood. Paper presented at the First APQUEN conference, Enugu.

Omoluabi, P.F. (1999). Standardization of their communication inventories with Nigerian samples. Unpublished manuscript, Department of Psychology, University of Lagos.

Rho, J.J. (1989). Multiple factors contributing to marital satisfaction in Korean-American marriages and correlations with three dimensions of family life satisfaction-marital, parental, and self-satisfactions. Unpublished doctoral dissertation, Kansas State University

Rogge, R.D., \& Bradbury, T.N. (1999). Till Violence does us apart: the differing roles of communication and aggression in predicting adverse marital outcomes. Journal of Consulting and Clinical Psychology, 67 (3), 340.

Rowe, D. R. (2004). Social Learning and Marital Satisfaction. Human Development, 420.

Rhyne, D. (1981). Bases of marital satisfaction among men and women. Journal of Marriage and the Family, 43, 941-955

Stanley, S. M., Markman, H. J., St. Peters, M., \& Leber, B. D. (1995). Strengthening Marriages and preventing divorce: New directions in prevention research. Family Relations, 44, 392-401.

Schumm, W. R., Webb, F. J., \& Bollman, S. R. (1998). Gender and marital satisfaction: Data from the national survey of families and households. Psychological Reports, 83, 319-327.

Tzeng, M. (1992). The effects of socioeconomic heterogamy and changes on marital dissolution for the first marriages. Journal of marriage and the family, 54, 609-619.

Walker, A. J. (1999). Gender and family relationships. In M. B. Sussman, S. K. Steinmetz, \& G. W. Peterson (Eds.). Handbook of marriage and the family, (2nd ed., pp. 439-474). New York: Plenum Press 